\title{
Joint Polar Satellite System
}

\author{
Timothy Trenklea . Phillip Driggers ${ }^{b}$ \\ ${ }^{a}$ NASA Goddard Space Flight Center, USA \\ ${ }^{b}$ Bastion Technologies, Inc., USA
}

\begin{abstract}
The Joint Polar Satellite System (JPSS) is a joint NOAA/NASA mission comprised of a series of polar orbiting weather and climate monitoring satellites which will fly in a sun-synchronous orbit, with a 1330 equatorial crossing time. JPSS resulted from the decision to reconstitute the National Polar-orbiting Operational Environmental Satellite System (NPOESS) into two separate programs, one to be run by the Department of Defense (DOD) and the uther by NOAA. This decision was reached in early 2010 , after numerous development issues caused a series of unacceptable delays in launching the NPOESS system.
\end{abstract}

Keywords: JPSS, climate, weather

\section{INTRODUCTION}

Polar orbiting satellites have been a key component of accurate weather forecasting and climate study for many years. NOAA estimates that without information from the current polar orbiting weather satellites, the massive snowstorm that struck the East Coast of the United States in February 2010 would have been under-estimated by 10 inches or more.' Without these satellites, tornado formation prediction and hurricane track forecasting would also suffer. The JPSS is intended to continue a four decade system of polar orbiting remote sensing and will represent a return to the civil-only polar weather satellite system abandoned in the mid-1990s in favor of a combined civil and military system. Using the lessons learned in the development of the sensors for NPOESS, as well as on-orbit lessons from the NPOESS Preparatory Project (NPP), JPSS will greatly improve the present capabilities with enhanced remote sensing capabilities and improved data latency.

\section{PROGRAM HISTORY; NPOESS - JPSS}

For roughly 30 years prior to 1994, the United States had two major polar orbiting weather programs; the Pular Operational Environmental Satellite (POES) program operated by the Department of Commerce (DOC) and the Defense Meteorological Satellite Program (DMSP) operated by the Department of Defense. In 1994, a review of these two programs, initiated during the Clinton administration, recommended that the two programs be merged into a single polarorbiting system with the rationale that a single system would leverage the synergies between the existing separate programs for a more cost-effective program. A plan for the merged program was submitted to the U.S. Congress in May 1994 and a Presidential Directive mandating the NPOESS program was signed by President Clinton in May 1994. ${ }^{2}$ A tri-agency (DOC, DOD, and NASA) Integrated Program Office (IPO) was created in October 1994 to manage the NPOESS program. At first order, NOAA (DOC) would be responsible for overall program management and operating the satellites after launch, DOD would have the responsibility for major acquisitions and NASA would be responsible for new technology infusion into the program.

The NPOESS program was intended to provide a single, space-based, polar-orbiting system to satisfy both civil and military requirements to acquire and distribute global and regional environmental data. To accomplish this, NPOESS 
planned a series of six satellites with a maximum of three operating at any time in 3 orbit planes: an early morning (1730 Local Time Ascending Node (LTAN) crossing), mid-morning (2130 LTAN crossing), ęarly afternoon (1330 LTAN crossing) orbit with the first launch scheduled for 2008. The contracts for the Ozone Mapping and Profiler Suite (OMPS), Cross-Track Infrared Sounder (CrIS) and Visible/Infrared Imager Radiometer Suite (VIIRS) instruments were awarded by the IPO in 2000 and the NPOESS spacecraft and system integration (satellite and ground segment) contract was awarded in 2002. The Advanced Technology Microwave Sounder (ATMS) instrument was developed by NASA as an evolution of the Advanced Microwave Sounding Unit (AMSU) sensors flown on the POES satellites.

NPOESS also intended to incorporate new technology to increase accuracy and timeliness of weather forecasts. As part of this new technology infusion, NPP was proposed in 1999. NPP was planned as a joint IPO/NASA mission, originally targeted for a 2006 launch into a 1030 Local Time Descending Node (LTDN) orbit, and was to serve as risk reduction for NPOESS sensors, technology, operations and operational data product generation. NPP was also intended to provide data continuity for NASA Earth Observing System (EOS) global imaging and sounding observations. NPP as originally conceived would be a research satellite flying the OMPS, VIIRS, CrIS and ATMS sensors and would use the Command, Control and Communications (C3) infrastructure developed for NPOESS.

\subsection{NPOESS Re-Organized Due To Nunn-McCurdy Breach}

A series of difficulties in instrument development resulted in significant schedule delays and cost over-runs and in December 2005, the NPOESS program notified Congress that NPOESS was in-breach of Nunn-McCurdy ${ }^{*}$ (greater than or equal to $25 \%$ cost over-run ${ }^{3}$ ) and would need to be recertified. As a result of this recertification, the NPOESS program was restructured. The restructured program eliminated the 2130 orbit spacecraft and associated instruments (and reduced the planned number of satellites from six to four), delayed the launch of NPP and the first NPOESS satellite by about 2 years and the number of manifested instruments was significantly reduced. Among the instrument reductions were: the planned Space Environmental Sensor Suite (SESS) would be replaced by the previously developed Space Environment Monitor (SEM) instrument; the planned Earth Radiation Budget Sensor (ERBS) would be replaced by the previously developed Clouds and Earth's Radiant Energy System (CERES instrument, first flown on the Tropical Rainfall Measurement System (TRMM) satellite); and the planned Total Solar Irradiance Sensor (TSIS) and Aerosol Polarimetry Sensor (APS) instruments would no longer be flown on NPOESS. It was also during this time that the decision to fly CERES instrument Flight Model 5 (built, tested and in storage since 2005), on NPP was made and NPP's orbit was officially changed to a 1330 orbit.

\subsection{NPOESS Becomes JPSS and DWSS}

Continued development issues after the Nunn-McCurdy restructuring led to the formation of an Independent Review Team (IRT) in 2009. The charter of the IRT was to investigate three areas of concern: the efficacy of the tri-agency management structure; identification of specific risk areas and an assessment of the readiness of the NPOESS program to proceed to production. The IRT concluded that the NPOESS program would require significant managerial and funding changes to have any possibility of succeeding and further concluded that the continuity of the four decade environmental data record was at risk. In response to the IRT findings, the Office of Science and Technology Policy (OSTP), along with the Office of Management and Budget (OMB) and the U.S National Security Council (NSC) and representatives from DOC, DOD and NASA studied options to address the IRT concerns. As a result of this study, it was recommended that the combination of civil and military polar weather program that resulted in NPOESS be dissolved back to separate programs.

\footnotetext{
- The Nunn-McCurdy law requires DOD to take specific actions, including recertification, when a major defense acquisition exceeds certain legislatively mandated cost thresholds.
} 
In February 2010, the Joint Polar Satellite System (JPSS) was created to provide the civil weather and climate measurements formerly planned for NPOESS and the Defense Weather Satellite System (DWSS) will provide the military weather capabilities planned for NPOESS. The JPSS ground system will service both the JPSS and the DWSS satellites.

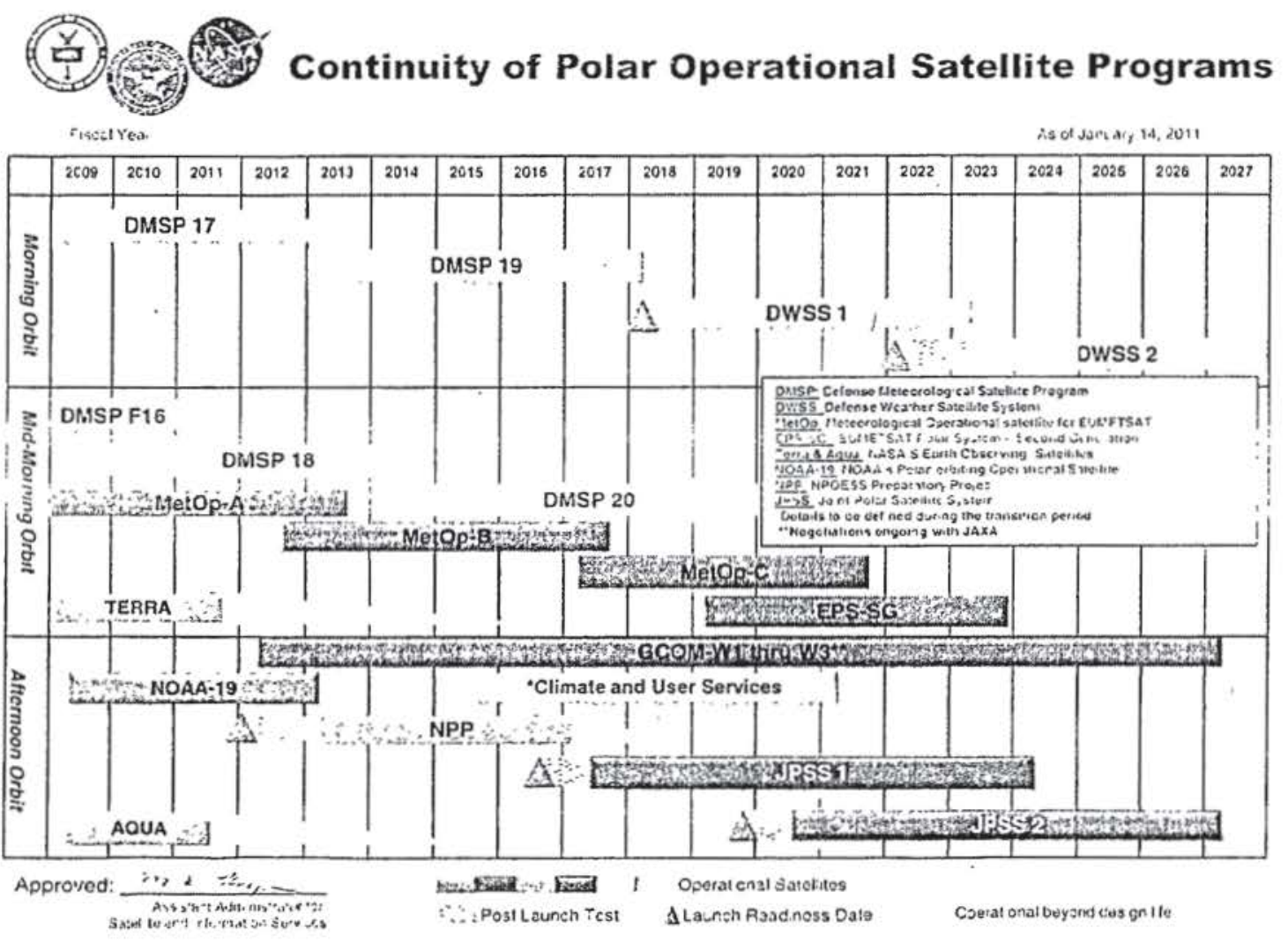

Figure 1 - Polar Satellite Data Continuity

\section{JPSS MISSION OVERVIEW AND TIMELINE}

The NASA/NOAA relationship on JPSS is modeled after the successful arrangement used on the POES and Geostationary Operational Environmental Satellite (GOES) programs with NASA acting as the acquisition agent for NOAA for the JPSS assets. JPSS as currently configured will consist of two sequentially launched, afternoon (1330 LTAN) orbiting, sun-synchronous satellites at 824 kilometers altitude. The first JPSS launch is planned for late 2016 with JPSS-2 scheduled for launch late this decade. The data products that JPSS will generate appear in Figure 2. In addition to the primary JPSS-1 and JPSS-2 series, a Free Flyer project has been set up to provide flight opportunity for TSIS, Search and Rescue Repeater (SARR)-Search and Rescue Processor (SARP) and Advanced Data-Collection Sỳstem (ADCS). 


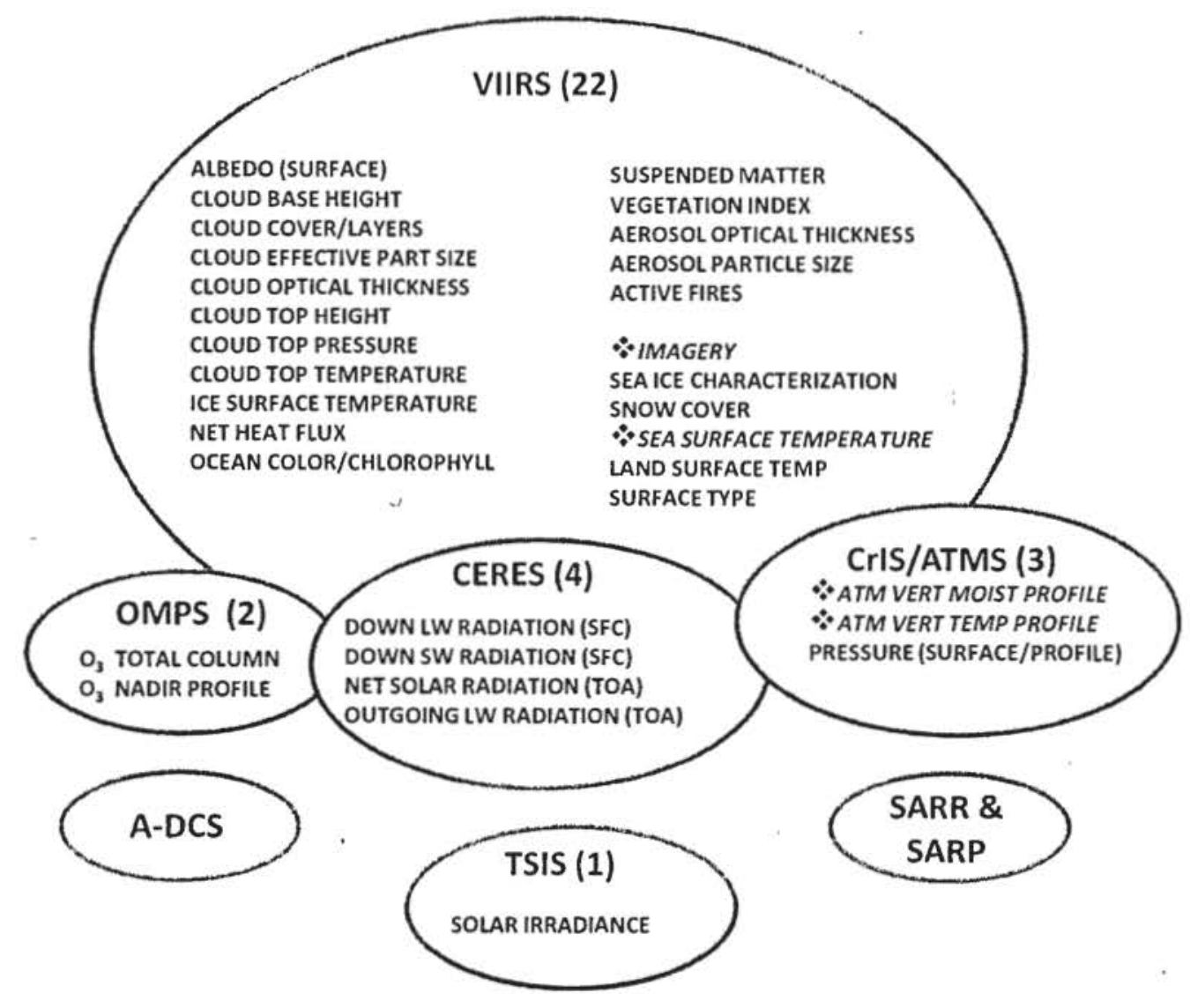

\section{KEY $\stackrel{\text { EDRs with Key Performance Parameters }}{\square}$ JPSS-1
(Host TBD)}

Figure 2 - JPSS Data Products

\subsection{JPSS-1 Mission Architecture}

The JPSS mission architecture will include both a space segment and ground segment. The space segment for JPSS-1 will consist of the same sensor complement as on NPP (VIIRS. ATMS. CrIS. CERES and OMPS) except that the OMPS-Limb sensor on NPP has been removed from JPSS. Section 4 below will describe some of the improvements to the JPSS instruments as a result of the lessons learned on NPP. The JPSS-1 spacecraft will be an NPP spacecraft "clone" with evolutionary technology upgrades and the addition of a gimbaled, Ka-band antenna. The Ka downlink will interface with the JPSS Ka-band Distributed Receptor Network (DRN). The DRNs will be spaced to allow frequent downlinks of 'data each orbit sufficient to meet the JPSS data latency requirements ( 80 minutes for JPSS-1 and 30 minutes for JPSS-2). The ground segment, which will support JPSS, DWSS and other future and legacy satellites, will 
consist of the mission operations center, an instrument data processing system for data product generation and long-term archive for the data products, and algorithm data product validation. The ground system will interface to the JPSS space segment through the DRNs and will output the processed data products to the various user communities. After each JPSS satellite is commissioned on-orbit, NOAA will assume day-to-day operational control of the satellite. This, like the procurement arrangement discussed above, mirrors the arrangement successfully used over many years on the POES program.

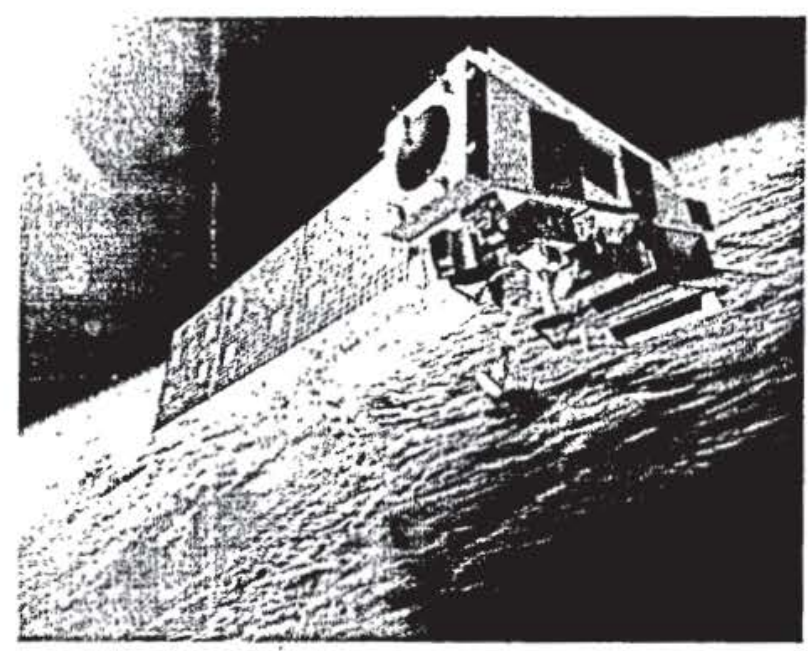

Figure 3 - JPSS-1 Satellite

\subsection{JPSS Timeline}

JPSS-1 is scheduled to be ready for launch in late 2016. A Program Concept Review was held in March 2011 and a Systems Requirements Review is scheduled for early 2012. At the time of the transition from NPOESS to JPSS, the sensors were well along in their development in support of an anticipated 2014 launch of the first NPOESS satellite. This development has continued since the transition albeit at a slower pace due to current JPSS funding levels. The JPSS-1 spacecraft, an NPP-clone, has been awarded to Ball Aerospace, with a spacecraft Critical Design Review planned for late 2012. A series of reviews is in work to assess the design and workmanship of the in-progress JPSS-1 instruments. These reviews are expected to complete in the Fall of 2011.

\section{SENSORS}

The sensor suite on JPSS-1 comprises the VIIRS, the CrIS, the ATMS, the OMPS, and the CERES. Together, these five sensors produce a wide variety of science data products providing both accurate weather forecasting capability and monitoring of a large number of environmental factors. At the top level, the purpose of each of these sensors is as follows:

VIIRS: collects measurements of clouds, aerosols, ocean color, surface temperature, tires, and albedo

CrlS: produces water vapor and temperature profiles of the atmosphere

ATMS: provides all-weather sounding profiles of atmospheric temperature and moisture 
OMPS: measures the global distribution of $\mathrm{O} 3$ (Ozone) in the stratosphere

CERES: measures the Earth's energy balance for a better understanding of global climate change

The following sections will describe each of these sensors in greater detail.

\subsection{VIIRS (Visible/Infrared Imager Radiometer Suite)}

The VIIRS sensor, developed by Raytheon Space and Airborne Systems in EI Segundo, California, USA, is a scanning radiometer that provides science from the visible to the long wave infrared $(0.4 \mu \mathrm{m}-12.4 \mu \mathrm{m})$. The VIIRS data is used for a wide variety of applications by the land, ocean, aerosol, and operational user communities, supporting 22 of the 31 Environmental Data Records (EDRs) that JPSS will produce (ref. Figure 2). It measures cloud and aerosol properties, ocean color, sea and land surface temperature, ice motion and temperature, fires, and Earth's albedo. It does so with a $18 \mathrm{~cm}$ rotating telescope to scan a $+/ .56$ degree, $300 \mathrm{~km}$ swath, every 1.9 seconds. In each rotation of the telescope, after the earth view, a series of calibrations are performed, including a black body view for infrared calibration, a solar diffuser view for visible wavelength calibration, and a deep space view. Incoming light is split into 22 spectral bands over 4 focal planes: a Visible and Near-Infrared (VISNIR) detector $(0.4 \mu \mathrm{m}-0.9 \mu \mathrm{m})$, a visible Day / Night Band (DNB) detector $(0.7 \mu \mathrm{m})$, a Short and Mid-Wave Infrared (SMWIR) detector $(1.2 \mu \mathrm{m}-4.1 \mu \mathrm{m})$, and a Long Wave Infrared Detector (LWIR) $(8.5 \mu \mathrm{m}-12.1 \mu \mathrm{m})$.

Table 1 - VIIRS Science Capabilities

\begin{tabular}{|c|c|c|c|c|c|c|c|c|c|c|c|}
\hline & & \multirow[t]{2}{*}{$\begin{array}{c}\text { Band } \\
\text { No. }\end{array}$} & \multirow{2}{*}{$\begin{array}{l}\text { Wave- } \\
\text { length } \\
\text { (jm) }\end{array}$} & \multicolumn{2}{|c|}{$\begin{array}{c}\text { Horiz Sample Interval } \\
\text { (km Downtrack } \times \text { Crosstrack) }\end{array}$} & \multirow[t]{2}{*}{ Driving EDRs } & \multirow{2}{*}{$\begin{array}{c}\text { Radi- } \\
\text { ance } \\
\text { Range }\end{array}$} & \multirow[t]{2}{*}{$\begin{array}{l}\text { Ltyp or } \\
\text { Ttyp }\end{array}$} & \multicolumn{3}{|c|}{$\begin{array}{l}\text { Signal to Noise Ratio } \\
\text { (dimensionless) } \\
\text { or NEST (Kelvins) }\end{array}$} \\
\hline & & & & Nadir & End of Scan & & & & Reguired & Predicted & Margin \\
\hline \multirow{9}{*}{ 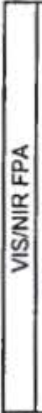 } & \multirow{9}{*}{ 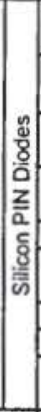 } & M1 & 0412 & $0742 \times 0259$ & $160 \times 158$ & $\begin{array}{c}\text { Ocean Color } \\
\text { Aerosols }\end{array}$ & $\begin{array}{l}\text { Low } \\
\text { High }\end{array}$ & $\begin{array}{l}449 \\
155 \\
\end{array}$ & $\begin{array}{l}352 \\
316 \\
\end{array}$ & \begin{tabular}{|l|}
441 \\
807 \\
\end{tabular} & $\begin{array}{c}25 \% \\
155 \% \\
\end{array}$ \\
\hline & & M2 & 0445 & $0742 \times 0259$ & $160 \times 158$ & $\begin{array}{l}\text { Ocean Color } \\
\text { Aerosols }\end{array}$ & $\begin{array}{l}\text { Low } \\
\text { High }\end{array}$ & $\begin{array}{c}40 \\
146 \\
\end{array}$ & $\begin{array}{l}380 \\
409 \\
\end{array}$ & $\begin{array}{l}524 \\
926 \\
\end{array}$ & $\begin{array}{r}38 \% \\
126 \% \\
\end{array}$ \\
\hline & & M3 & 0.488 & $0.742 \times 0259$ & $160 \times 1.58$ & $\begin{array}{c}\text { Ocean Color } \\
\text { Aerosols }\end{array}$ & $\begin{array}{l}\text { Low } \\
\text { High }\end{array}$ & $\begin{array}{c}32 \\
123 \\
\end{array}$ & $\begin{array}{l}416 \\
414 \\
\end{array}$ & $\begin{array}{l}542 \\
730 \\
\end{array}$ & $\begin{array}{l}30 \% \\
76 \%\end{array}$ \\
\hline & & M4 & 0.555 & $0.742 \times 0.259$ & $160 \times 158$ & $\begin{array}{l}\text { Ocean Color } \\
\text { Aerosols }\end{array}$ & $\begin{array}{l}\text { Low } \\
\text { High }\end{array}$ & $\begin{array}{l}21 \\
90\end{array}$ & $\begin{array}{l}362 \\
315\end{array}$ & $\begin{array}{l}455 \\
638 \\
\end{array}$ & $\begin{array}{l}26 \% \\
102 \%\end{array}$ \\
\hline & & 11 & 0640 & $0371 \times 0387$ & $080 \times 0789$ & Imagery & Single & 22 & 119 & 146 & $23 \%$ \\
\hline & & M5 & 0672 & $0742 \times 0.259$ & $1.60 \times 1.58$ & $\begin{array}{c}\text { Ocean Color } \\
\text { Aerosols }\end{array}$ & $\begin{array}{l}\text { Low } \\
\text { High }\end{array}$ & $\begin{array}{l}10 \\
68\end{array}$ & $\begin{array}{l}242 \\
360 \\
\end{array}$ & $\begin{array}{l}298 \\
522\end{array}$ & $\begin{array}{l}23 \% \\
45 \% \\
\end{array}$ \\
\hline & & M6 & 0.746 & $0742 \times 0776$ & $160 \times 158$ & Atmospheric Corr'n & Single & 96 & 199 & 239 & $20 \%$ \\
\hline & & 12 & 0865 & $0371 \times 0387$ & $0.80 \times 0.789$ & NDVI & Single & 25 & 150 & 225 & $50 \%$ \\
\hline & & M7 & 0.865 & $0.742 \times 0259$ & $160 \times 1.58$ & $\begin{array}{l}\text { Ocean Color } \\
\text { Aerosols }\end{array}$ & $\begin{array}{l}\text { Low } \\
\text { High }\end{array}$ & $\begin{array}{c}6.4 \\
334 \\
\end{array}$ & $\begin{array}{l}215 \\
340\end{array}$ & $\begin{array}{l}388 \\
494 \\
\end{array}$ & $\begin{array}{l}81 \% \\
45 \%\end{array}$ \\
\hline $\mathrm{CC}$ & DI & DNB & 07 & $0742 \times 0742$ & $0742 \times 0742$ & Imagery & Var. & $6.70 \mathrm{E}-05$ & 6 & 57 & $.5 \%$ \\
\hline \multirow{8}{*}{$\mid$} & & M8 & 124 & $0742 \times 0776$ & $160 \times 1.58$ & Cloud Particle Size & Single & 5.4 & 74 & 98 & $32 \%$ \\
\hline & E & M9 & 1378 & $0742 \times 0776$ & $160 \times 158$ & Cirrus/Cloud Cover & Single & 6 & 83 & 155 & $88 \%$ \\
\hline & ㄴㅟㅚ & 13 & 1.61 & $0.371 \times 0.387$ & $080 \times 0.789$ & Binary Snow Map & Single & 7.3 & 6.0 & 97 & $1523 \%$ \\
\hline & of & $\mathrm{M} 10$ & 1.61 & $0742 \times 0.776$ & $160 \times 158$ & Snow Fraction & Single & 73 & 342 & 439 & $28 \%$ \\
\hline & 5 & M11 & 225 & $0.742 \times 0.776$ & $160 \times 158$ & Clouds & Single & 0.12 & 10 & 17 & $66 \%$ \\
\hline & 요 & 14 & 374 & $0371 \times 0387$ & $080 \times 0789$ & Imagery Clouds & Single & $270 \mathrm{~K}$ & 2500 & 0486 & $415 \%$ \\
\hline & 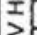 & M12 & 3.70 & $0.742 \times 0.776$ & $160 \times 158$ & SST & Single & $270 \mathrm{~K}$ & 0396 & 0218 & $82 \%$ \\
\hline & 2 & M13 & 4.05 & $0.742 \times 0259$ & $1.60 \times 1.58$ & $\begin{array}{l}\text { SST } \\
\text { Fires }\end{array}$ & $\begin{array}{l}\text { Low } \\
\text { High }\end{array}$ & $\begin{array}{l}300 \mathrm{~K} \\
380 \mathrm{~K} \\
\end{array}$ & $\begin{array}{l}0.107 \\
0423 \\
\end{array}$ & $\begin{array}{l}0.063 \\
0.334 \\
\end{array}$ & $\begin{array}{l}69 \% \\
27 \% \\
\end{array}$ \\
\hline \multirow{4}{*}{$\underset{\sim}{\underline{s}}$} & & M14 & 8.55 & $0742 \times 0.776$ & $160 \times 158$ & Cloud Top Properties & Single & $270 \mathrm{~K}$ & 0091 & 0.075 & $22 \%$ \\
\hline & 오 & M15 & 10763 & $0.742 \times 0.776$ & $160 \times 158$ & SST & Single & $300 \mathrm{~K}$ & 0.070 & 0.038 & $85 \%$ \\
\hline & $>$ & 15 & 11450 & $0.371 \times 0.387$ & $080 \times 0789$ & Cloud Imagery & Single & $210 K$ & 1500 & 0.789 & $90 \%$ \\
\hline & 2. & M16 & 12013 & $0742 \times 0776$ & $160 \times 158$ & SST & Single & $300 \mathrm{~K}$ & 0.072 & 0051 & $42 \%$ \\
\hline
\end{tabular}

While each of the 22 EDRs represents an important application, discussing each would make for a prohibitively long paper. Instead, we will focus on the two mission Key Performance Parameters (KPP) of Sea Surface Temperature and Imaging. 
Sea Surface Temperature and Ocean Color

I Sea Surface Temperature (SST) has been identified as one of the 4 Key Performance Parameters (KPP) for the JPSS-1 mission. Accurate estimates of SST are essential for many applications such as hurricane prediction and weather forecasting because temperature plays an important role in the formation of currents, ocean fronts, and water masses. It is also important in ecological applications such as detection of areas at high risk for coral bleaching. Longer term tracking of SST provides valuable information about long-term climate change. The U.S. Navy and other users such as fisheries will rely on VIIRS SST and ocean color products to help with ocean optical forecasts. Uses for these products include assessment of water clarity, tracking of algae blooms and changes in phytoplankton concentrations. The spatial resolution of VIIRS (400m @ Nadir, 800m @ Edge of Scan) will provide a substantial improvement over Moderate Resolution Imaging Spectrometer (MODIS) and Sea-viewing Wide Field-of-view Sensor (SeaWiFS) in the monitoring of these important ocean characteristics.

\section{Cloud Imagery}

Cloud properties such as cloud top height and moisture and / or ice content are best measured by using an imager in concert with a sounder. VIIRS imagery will be used with the data from CrIS to supply a large, diverse user community with cloud data. This data is very important for near-term and mid-term weather forecasting, as well as long-term studies of cloud properties. Relative to predecessor sensors such as Advanced Very High Resolution Radiometer (AVHRR), High Resolution Infrared Sounder (HIRS), MODIS, and Atmospheric Infrared Sounder (AIRS) that have contributed to the many decades long cloud record, VIIRS and CrIS will provide better calibrated data at a higher spatial resolution, providing an improved contribution to the climate data record.
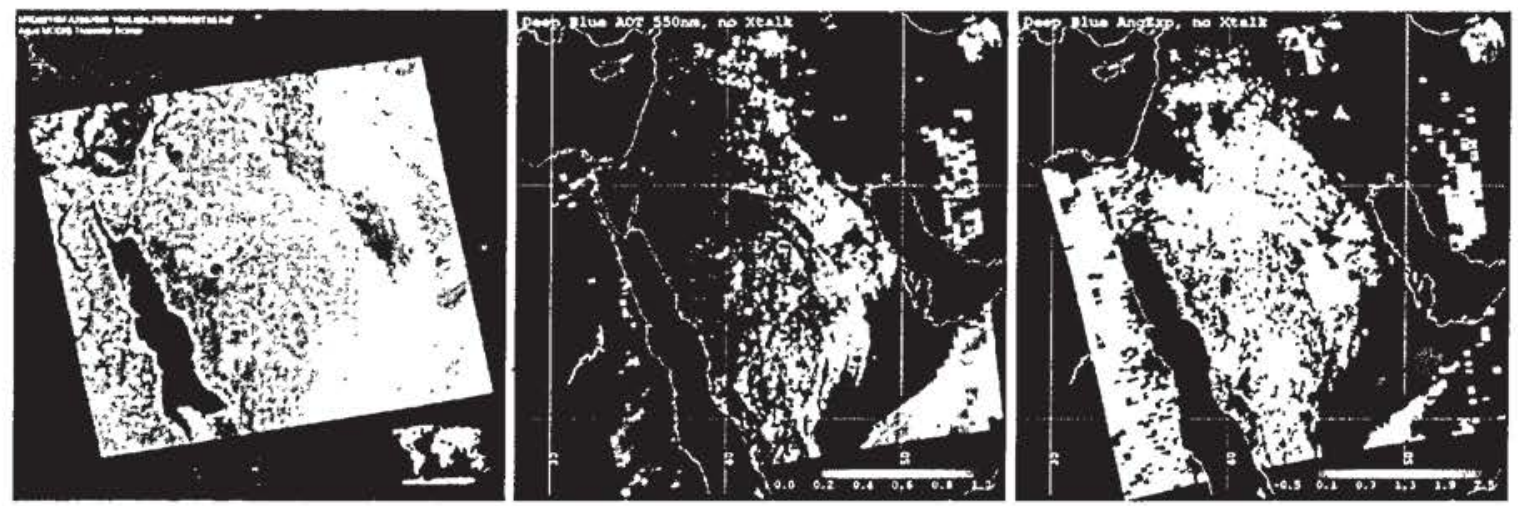

Figure 4 -MODIS image of dust storm in Persian Gulf seen in visible and infrared

\section{VIIRS Heritage and Improvements Since NPP}

The NPP VIIRS extends and improves upon a series of measurements initiated by AVHRR and MODIS. It is expected that the JPSS-I VIIRS will be improved, even relative to the NPP VIIRS. On NPP, there were several problems that have subsequently been corrected, including minimizing optical cross talk between bands on the VISNIR detector, minimizing Wave Front Error shifts in the telescope due to temperature variation during the orbit, and removing power from a dichroic to ensure that all focal planes are confocal. Electronics changes were made to improve noise performance and overall reliability. The VISNIR focal plane array should provide improved Signal to Noise and reduced dynamic cross talk compared to NPP. Work was also done to improve the symmetry of the line-spread function in the infrared focal plane arrays. In addition, several improvements to the test equipment and methodology are being considered which could yield improved radiometric measurement accuracy.

\subsection{CrIS (Cross Track Infrared Sounder)}

The CrIS sensor, developed by ITT in Fort Wayne, Indiana, USA, is a Fourier transform spectrometer that produces 3 dimensional atmospheric temperature, moisture and pressure profiles. Working in tandem with the ATMS sensor, it 
provides 3 EDRs, 2 of which have been identified as mission KPPs: Atmospheric Vertical Moisture Profile, and Atmospheric Vertical Temperature Profile, both of which are critical for accurate weather forecasting. It will also provide complimentary data to the VIIRS cloud data. CrIS produces 1305 spectral channels from 3 focal planes. which cover the short wave infrared $(3.9 \mu \mathrm{m}-4.7 \mu \mathrm{m})$, mid-wave infrared $(5.7 \mu \mathrm{m}-8.3 \mu \mathrm{m})$, and long wave infrared $(9.1 \mu \mathrm{m}$ $-15.4 \mu \mathrm{m}$ ). Each focal plane is made up of 9 photovoltaic detectors arrayed as a $3 \times 3$ field of view (FOV) array corresponding to an earth surface spot with diameter 14 kilometers. CrIS scans a $2200 \mathrm{~km}$ swath width (+/- 50 degrees), with 30 Earth-scene views. Each scan (with an 8-second repeat interval) includes views of the internal calibration target (warm calibration point), and a deep space view (cold calibration point).

\section{CrlS Heritage and Improvements Since NPP}

CrIS has heritage to the HIRS instrument on POES. Improvements since NPP include increasing the reliability of multiple structural elements, by changing multi-piece brazed units with a new one piece machined AlBeMet $\circledast$ frame and one piece machined Beryllium optical bench. The black body calibrator used on NPP has been replaced with a new 3bounce trap that will increase performance while greatly reducing the sensitivity to surface properties compared to the NPP black body.

\subsection{ATMS (Advanced Technology Microwave Sounder)}

The ATMS is a cross track microwave scanner developed by Northrop Grumman Electronic Systems in Azusa, California, USA. Using 22 channels from $23 \mathrm{GHz}$ to $183 \mathrm{GHz}$, it produces the two KPP products, atmospheric temperature, moisture, as well as pressure profiles even in presence of clouds. The channels are spaced along atmospheric absorption lines, allowing sensing at different altitudes. Since clouds get more transparent as you go from the infrared into the microwave, taking data across both parts of the spectrum together makes it possible to cover a much broader range of weather conditions than with either a microwave or infrared sounder alone. For this reason, the ATMS data is used in conjunction with CrIS data to provide a more complete view of atmospheric conditions.

\section{ATMS Heritage and Improvements Since NPP}

The ATMS traces its heritage to the AMSU sensors flown on POES. The AMSU consisted of 2 sub-instruments, AMSU-A ( 15 channels between 23 and $89 \mathrm{GHz}$ used primarily for atmospheric temperatures) and AMSU-B ( 5 channels between 89 and $183 \mathrm{GHz}$ used primarily for atmospheric moisture). ATMS has 22 channels, mostly the same wavelength as its predecessors, with a few modifications and additions. ATMS combines all of the channels of its predecessors (AMSU-A and AMSU-B) into a single sensor that is substantially smaller and more efficient, with only $1 / 4$ the volume, $1 / 2$ the mass, and $1 / 2$ the orbit average power. ATMS also eliminated gaps between adjacent swaths, substantially improving the spatial coverage provided by the AMSU predecessor. Relative to NPP, the JPSS-1 ATMS has been only slightly changed to improve the overall reliability of the ATMS sensor. The science performance of the sensor will be unchanged relative to NPP.

\subsection{OMPS (Ozone Mapping Profiler Suite)}

OMPS. developed by Ball Aerospace and Technologies Corp. in Boulder. Colorado. USA. uses UV and visible hyperspectral instruments to measure the global distribution of ozone, providing crucial data to support monitoring of ozone health, and an important link in the continuity of $25+$ years of ozone measurement. OMPS is responsible for providing 2 EDRs. It is comprised of two sensors: a nadir mapper with about $50-\mathrm{km}$ ground-resolution to map global ozone, and a nadir profiler to measure the vertical distribution of ozone in the stratosphere. The instruments in OMPS detect ozone by taking advantage of the fact that ozone absorbs ultra-violet radiation. By measuring the spectra of light reflected off of the atmosphere and looking for signature absorption features, ozone is detected. The improved vertical resolution of OMPS data products relative to OMPS predecessors allows for better testing and monitoring of the complex chemistry involved in ozone destruction near the troposphere. OMPS products, when combined with cloud predictions, alșo help produce better ultraviolet index forecasts. ${ }^{4}$ 


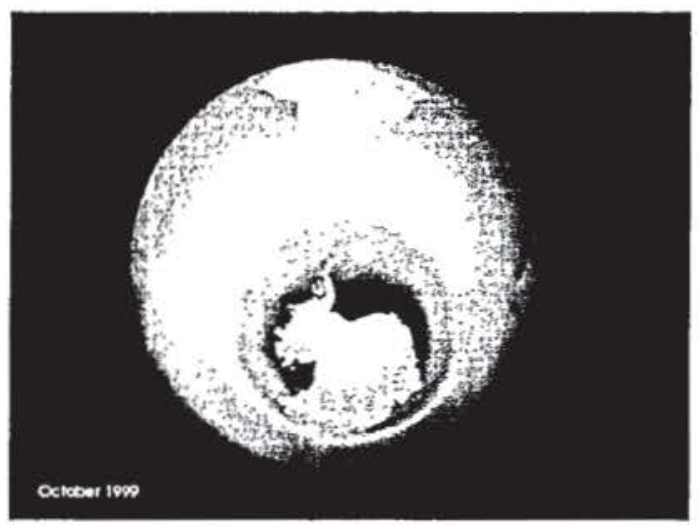

Figure 5 : Data from the Total Ozone Mapping Spectrometer (TOMS) Earth Probe, for the month of October 1999.

\section{OMPS Heritage and Changes since NPP:}

OMPS traces it's heritage to Solar Backscatter Ultraviolet (SBUV and SBUV/2) and the Total Ozone Mapping Spectrometer (TOMS) instruments, which flew on various NASA, NOAA, and international satellites. The major difference between the JPSS-1 OMPS and the NPP OMPS is that due to funding constraints, the JPSS-1 OMPS will not include a Limb sensor. The NPP solar diffuser (used to track sensor sensitivity changes with respect to the input solar flux) is being upgraded on JPSS to employ a Quasi Volume Diffuser (QVD) to improve calibration. QVDs have previously been used successfully in similar applications. There are also a number of changes that should improve reliability.

\subsection{CERES (Cloud's and Earth's Radiant Energy System)}

CERES is a radiometer that helps track the Earth's energy budget, the balance of incoming energy and outgoing energy, by measuring solar-reflected and earth-emitted thermal radiation. The sensor's 3 channels of data from 3 bolometers cover the short wave $(0.3 \mu \mathrm{m}-5 \mu \mathrm{m})$ to measure the reflected sunlight, long wave $(5 \mu \mathrm{m}-50 \mu \mathrm{m})$ to measure Earth emitted heat, and a total channel $(0.3 \mu \mathrm{m}->50 \mu \mathrm{m})$. A set of calibrations is performed during each scan cycle using onboard calibration sources comprising a tungsten lamp, a solar diffuser, two blackbodies, and a view of deep space. CERES has cross-track and 360-degree azimuth biaxial scan angular sampling capabilities. It is responsible for providing 4 EDRs (see Figure 2), each of which is critical in monitoring and understanding long term climate change, and evaluation of the effects on the Earth's radiation budget and resultant climatic impacts from natural disasters such as volcanic eruptions and floods. CERES is developed by Northrop Grumman Aerospace Systems in Redondo Beach, California, USA and managed by the NASA Langley Research Center in Hampton, Virginia, USA.

\section{CERES Heritage and improvements since NPP}

The CERES on JPSS-1 will be the sixth CERES flown. CERES has flown before on TRMM, Terra, and Aqua. Relative to the fifth sensor on NPP, there have been several improvements that should yield higher quality science. Specifically, better stability of the Mirror Attenuator Mosaic (MAM), the CERES equivalent of a solar diffuser, is expected due to improved fabrication and coating techniques relative to previous CERES builds. The Short Wave in-flight calibration source has been modified to have substantially better radiation tolerance. The in-flight calibration will also be improved by a larger Blackbody temperature range. Additionally, the wavelength range for the Long Wavelength channel is being increased significantly, from $8-12 \mu \mathrm{m}$ (previous CERES) to $5-50 \mu \mathrm{m}$ (JPSS-1 CERES). 


\section{NPP STATUS AND LESSONS LEARNED}

The NPP satellite completed a full set of environmental testing in spring of 2011 in preparation for a planned October 2011 launch from Vandenberg Air Force Base. A series of end-to-end tests with the satellite and ground segment concluded in the summer of 2011. The long delays in the development of flight instruments for NPP allowed for many opportunities for interface testing between the flight spacecraft and high-fidelity instrument Engineering Development Units (EDUs). In addition to early (with respect to flight instrument delivery) identification and correction of spacecraft to instrument interface issues, these activities with the flight spacecraft and EDUs aiso resulted in significant opportunities for the NPP mission operations team to interact with the NPP satellite. Since the JPSS-1 spacecraft and instruments will be "clones" of their NPP counterparts, this early interface testing, intra-space segment and space-toground will not be as important on JPSS as it was on NPP, but JPSS will still need to consider what sort of early interface testing is needed as well as how to leverage the NPP in-flight lessons learned.

The NPP instruments, and by extension, the JPSS instruments, required cryogenic and/or radiometric target sources to effect end-to-end testing in satellite thermal-vacuum. Accommodation of these targets in the limited available volume in a thermal-vac chamber can be problematic and early consideration of these accommodations is paramount to successful implementation. Due to the similarities between NPP and JPSS-1 satellites, JPSS will be able to take advantage of the targets and associated support structure developed for NPP. A shortcoming in some of the instrument designs on NPP was the inability to stimulate the instruments under ambient conditions. This means that outside of the thermal-vacuum environment, only very limited functionality of some of the NPP instruments is able to be tested and verified. As the JPSS instruments are developed, JPSS will consider the addition of the capability to stimulate the instruments in ambient conditions.

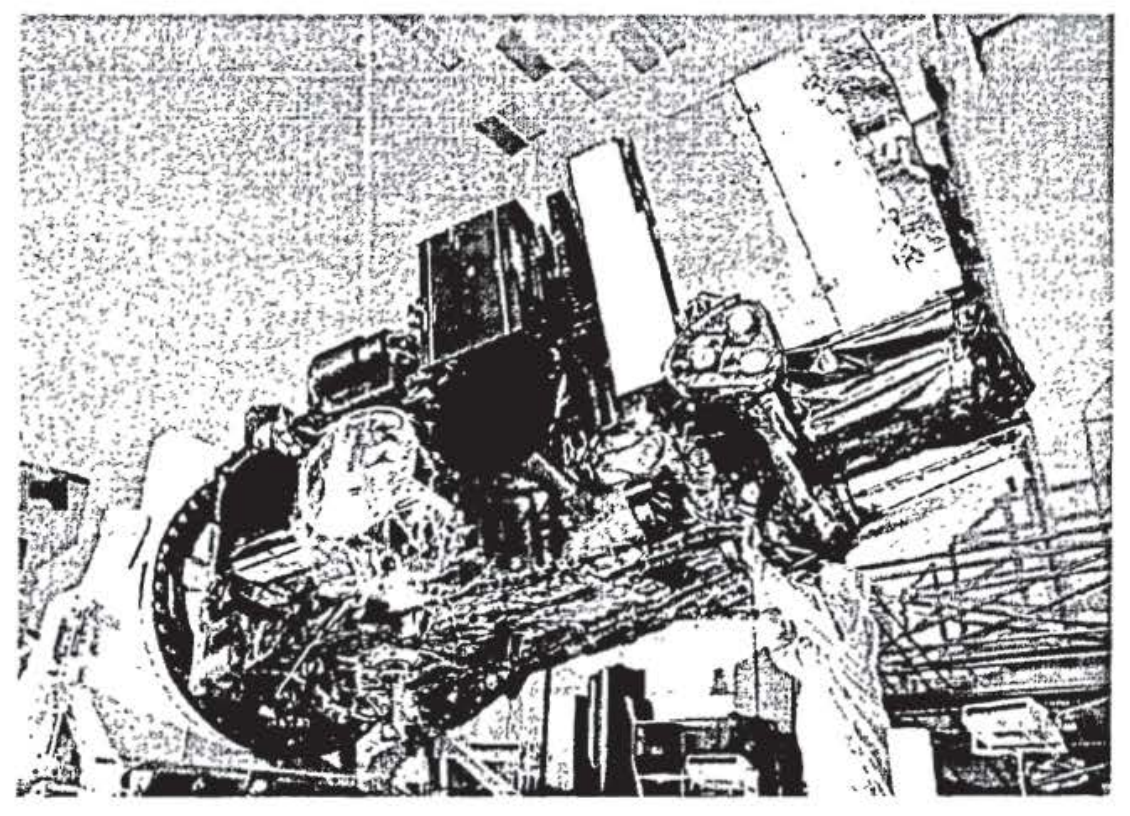

Figure 6-Fully Integrated NPP Satellite ${ }^{+}$

\footnotetext{
${ }^{\dagger}$ Courtesy Ball Aerospace Corporation
} 


\section{CONCLUSION}

JPSS will continue the decades long weather and climate measurements successfully performed by the POES program using polar-orbiting, remote-sensing satellites. It will implement lessons learned on the NPOESS program along with the experience gained through 40 years of POES operations to not only continue to add to. but also to improve the climate data record. JPSS will meet the needs of a wide array of scientists and real-time users, and will contribute to improving daily life for billions of people across the globe by providing enhanced weather prediction and climate understanding.

\section{REFERENCES}

${ }^{1}$ NOAA: Impact of Loss of US Polar-orbiting Satellite Data on Nation's High-Impact Weather Forecast Capability : A Case Study of the 5-6 Feb-2010 East Cuast Storm

${ }^{2}$ PRESIDENTIAL DECISION DIRECTIVE/NSTC-2

${ }^{3} 10$ U.S.C. $\$ 2433$ commonly referred to as Nunn-McCurdy

${ }^{4}$ NASA's NPP website: http://jointmission.gsfc.nasa.gov/ 